\title{
Aus dem GfA-Vorstand
}

\section{Rückblick Herbstkonferenz 2019: ERKENNEN.LERNEN.VERÄNDERN - Die Arbeit des Menschen in der digital vernetzten Welt}

In Kooperation mit der MTM ASSOCIATION e.V. und mit Unterstützung der Daimler AG fand die traditionelle Herbstkonferenz der GfA mit dem Titel „ERKENNEN.LERNEN.VERÄNDERN - Die Arbeit des Menschen in der digital vernetzten Welt" am 12. und 13. September in Böblingen statt.

Themen der Tagung waren:

- Ältere Beschäftigte in der digital vernetzten Welt

- Gestaltung menschlicher Arbeit in der digital vernetzten Welt

- Ergo-Productivity continuous improvement

- Das Industrial Engineering der Zukunft - Herausforderungen für die Arbeitswissenschaft

- Sicherheit und Gesundheit in der digitalen Arbeitswelt

- Einsatzmöglichkeiten und Grenzen von Exoskeletten

- Innovative Modelle und Methoden des Industrial Engineering zur Gestaltung menschlicher Arbeit

- Produktive Gestaltung der digitalisierten Arbeitswelt

- Arbeits- und leistungspolitische Perspektiven der Daimler AG

Die Moderation der zweitägigen Veranstaltung übernahmen die Herren Prof. Dr. Klaus Bengler (Präsident der Gesellschaft für Arbeitswissenschaft, Leiter Lehrstuhl für Ergonomie/Technische Universität München) sowie Prof. Dr.Ing. Peter Kuhlang (Leiter MTM-Institut, Hamburg).

Der Tagungsband ist online im Buchshop der GfA erhältlich (https://www.gesellschaft-fuer-arbeitswissenschaft. de/publikationen_gfa-buchshop.htm).

Mit 107 Teilnehmern war die Tagung sehr gut besucht. Wir bedanken uns für die Unterstützung bei allen Beteiligten, die diese Veranstaltung zu einem großen Erfolg machte.

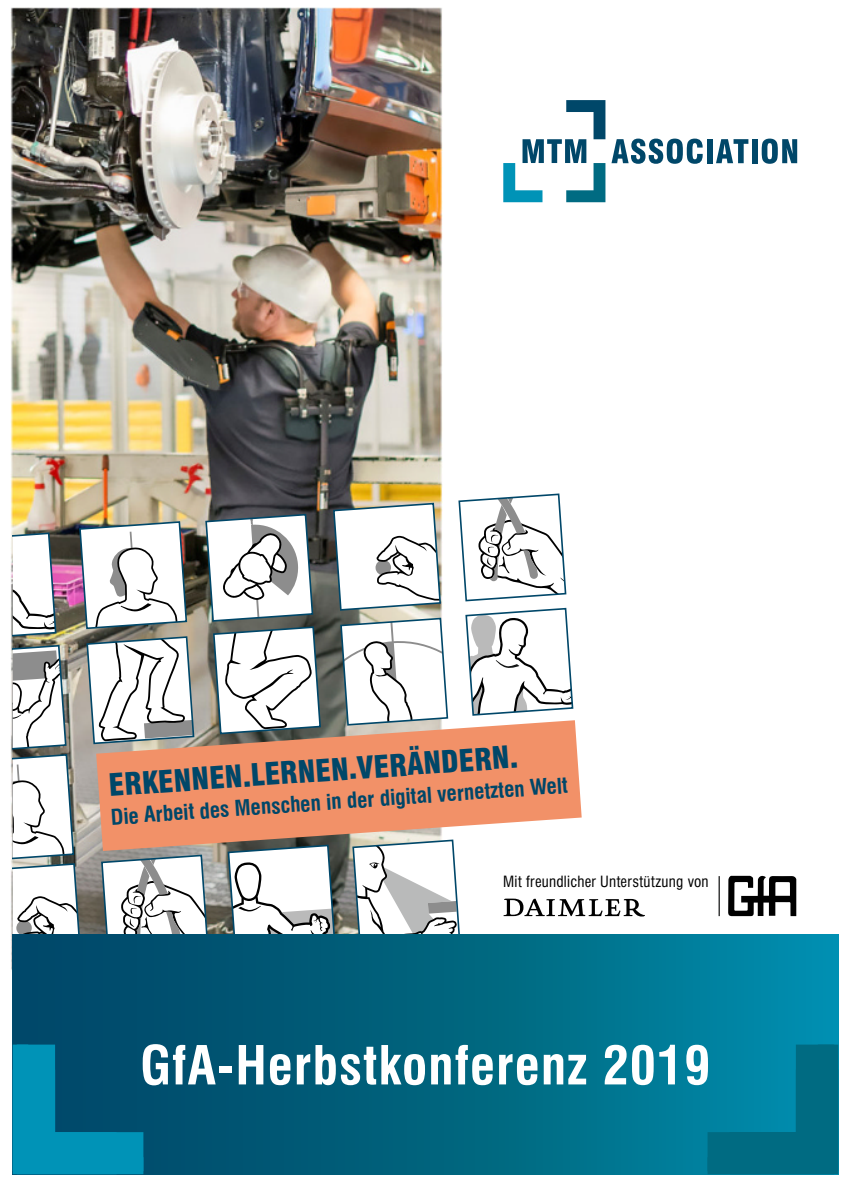

